\title{
ROLE OF ANTIDEPRESSANTS AGAINST LEISHMANIASIS
}

\author{
KEYA MALLICK, SUGATO BANERJEE ${ }^{*}$ iD
}

Department of Pharmacology and Toxicology, National Institute of Pharmaceutical Education and Research, Kolkata, India Email: banerjeesugato1@gmail.com

Received: 21 Aug 2021, Revised and Accepted: 24 Dec 2021

ABSTRACT

The disease, Leishmaniasis is a forlorn, tropical, vector-borne disease caused by the kinetoplast protozoan, an obligate intracellular parasite of the class Leishmania, which is transmitted by the nibble of female sandfly (Phlebotomus). Leishmaniasis is an incurable rare disease, since the organism developed resistance towards the currently used drugs, including pentavalent antimonials, amphotericin B and miltefosine. The mechanisms involved in drug resistance include reduced expression and mutations in AQP1, mutations in miltefosine transporters like, LMT and/or LRos3 and increased expression of drug efflux transporters like, $\mathrm{ABC}$ transporters in the parasitic cells. Hence alternate therapeutics against leishmaniasis is the need of the hour. Here we discuss the therapeutic potential of antidepressants as potential antileishmanial agents.

Keywords: Leishmania, Antidepressants, Drug resistance, Tricyclics antidepressants

(c) 2022 The Authors. Published by Innovare Academic Sciences Pvt Ltd. This is an open access article under the CC BY license (https://creativecommons.org/licenses/by/4.0/) DOI: https://dx.doi.org/10.22159/ijpps.2022v14i3.43662. Journal homepage: https://innovareacademics.in/journals/index.php/ijpps.

\section{INTRODUCTION}

The disease, Leishmaniasis is a forlorn, tropical, vector-born disease caused by the kinetoplastid protozoan, an obligate intracellular parasite of the class Leishmania, which is transmitted by the nibble of female sandfly (Phlebotomus) [1]. There are certain numbers of unique types of sandflies that can transmit this parasite through their chomps [2]. There are three main forms of the disease, namely mucocutaneous leishmaniasis, visceral leishmaniasis or kala-azar and cutaneous leishmaniasis. Leishmaniasis may be fatal if left untreated and affects about half a million people worldwide, primarily caused by $L$. chagasi, $L$. infantum and L. donovani [3-5] (table 1).

Visceral leishmaniasis is endemic in the Indian subcontinent, especially in Bihar, Assam, Nepal, Bangladesh and some parts of West Bengal [6]. L. tropica and L. major are responsible, [7] for cutaneous leishmaniasis (CL). The sandfly injects the promastigote stage of this protozoan parasite into the skin. The promastigotes are phagocytosed by host macrophages or other types of mononuclear phagocytic cells and transform into amastigotes. In the Leishmania $s p$. parasitic cells, primarily four types of lipids, namely, phospholipids, free fatty acids, triglycerides and sterols, are present. These lipids are involved in the transformation process of promastigote to amastigote in the $L$. donovani [8]. If the parasite defeats the host innate immune response involving toll-like receptor-mediated signalling and oxidative burst, then only it can multiply in cells of various tissues and infect other cells. The sandfly bites at the amastigote stage, which transform into promastigotes and divide in the host macrophages and infect other mononuclear phagocytic cells $[9,10]$. Visceral leishmaniasis may cause asymptomatic infection to life-threatening illness. Typical manifestations of visceral leishmaniasis include weight loss, chronic fever, and hepatosplenomegaly. Postkala-Azar dermal leishmaniasis, involving skin irritation may persist even after effective treatment of visceral leishmaniasis [11]. Studies have indicated that helper T1 lymphocytes secreting interferon- $\gamma$, TNF- $\alpha$ are engaged in resistant reactions against leishmaniasis. In addition, a few investigators demonstrated that NK cells can decimate the parasites through interferon- $\gamma$ at the time of infection [12, 13]. Treatment failure, adverse side effects and resistance to the commonly used drugs like antimonials, Liposomal amphotericin $\mathrm{B}(\mathrm{AmB})$, containing azole ring [14] and miltefosine (MIL) remain a major obstacle for successful chemotherapeutic eradication of the disease $[15,16]$. As there are no ideal drugs or reasonable therapeutic options for irradicating this rare disease, it continues to be the cause of illness among individuals in the affected area and remains an unresolved problem $[17,18]$. Many drugs were used against leishmaniasis, but have become less effective due to the development of resistance and cases of relapse. Such resistance occurred due to improper dosing and altered thiol metabolism (antimonials) [19]. Antimonials also showed serious toxicity reports $[19,20]$. Like antimonials, patients on meltefosin also showed resistance and relapses [20-24]. In this review we will discuss the therapeutic activity and mechanisms of action for antidepressant drugs as anti-leishmanial [25]. Keywords used for searching articles in google scholar and PubMed from 1980-2021 include leishmania, leishmaniasis, antidepressants in leishmaniasis, drug resistance in leishmania, leishmaniasis therapy, tricyclics in leishmania.

\section{Drug resistance and leishmaniasis}

Reduced expression of AQP1, the carrier involved in transporting tetravalent antimony into the host cell, has been associated with pentavalent antimonial (Sodium stibogluconate) resistance [26]. AQP1 mutation renders the gene inactivity, which is related to decreased accumulation of antimony into the parasitic cells thus creating resistance. MRPA/PRP1 ABC (ATP-binding cassette) transporter overexpression involved in carrier-mediated transportation of various molecules across biological membranes has also been shown to be involved in resistance in antimonials by influencing the efflux of drugs out of the parasitic cells $[27,28]$. Increased expression of tryparedoxin peroxidase, which increases the levels of intracellular thiols has also been associated with resistance to antimonials.

After resistance to pentavalent antimonials, miltefosine has been the first-line drug against visceral leishmaniasis. However, the parasite has also been developing resistance against miltefosine, primarily due to the mutation of miltefosine transporters like LMT and/or LRos3 [29]. Increased levels of efflux transporters like, ABC transporters ABCB4 (MDR1), ABCG4, and ABCG6 leading to decreased intracellular drug accumulation in the parasitic cells also contribute towards miltefosine resistance. Mutations of genes encoding pyridoxal kinase and $\alpha$-adaptin and other proteins associated with membrane fluidity, oxidative stress, folate metabolism may also contribute towards miltefosine resistance. The parasite is also developing resistance against Amphotericin B, an established antifungal used as anti-leishmanial, primarily by alterations in parasitic cell membrane sterol content like replacement of ergosterol with cholesterols. Further details on the mechanism for parasitic resistance against anti-leishmanial has been discussed by Ponte-Sucre and his colleagues [29] fig 1. 


\section{Antidepressants against infectious disease}

Depression is a major public health concern affecting all age groups, especially the elderly. [30] Imipramine, clomipramine, lofepramine, nortriptyline, amitriptyline, desipramine are examples of TCAs (table 2) [31,32] Tricyclic compounds are generally utilized in the clinical setting, in the therapy of major depressive disorder since it inhibits 5-hydroxytryptamine (serotonin) and norepinephrine reuptake [33]. Tricyclic antidepressants (TCA) have been reported to show anti-fibrotic activity. It reduces fibrogenesis in hepatic stellate cells, $[34,35]$ and is efficient against fibrosis as well as nonalcoholic steatohepatitis (NASH) [34-36].

Besides the above actions, imipramine is known to have immunosuppressive properties by reducing incendiary cytokines and promoting autophagy in tumour cells $[37,38]$. Inflammation and antidepressants have a complex relationship. Imipramine treatment leads to a decrease in interleukin 6 but not in C-reactive protein and tumour necrosis factor-alpha [39-41]. Antidepressants appear to have a joint effect on the inflammatory response system (IRS), as these drugs increase the expression of interleukin 10, suggesting negative immune regulatory properties [42].

Antidepressants are also very effective against various infectious diseases. Imipramine, a tricyclic anti-depressant is active against Chikungunya virus (CHIKV). At a concentration of $100 \mu \mathrm{M}$, imipramine may prevent the replication of CHIKV [43].

FDA-approved antidepressants like trifluoperazine (TFP), amoxapine (AXPN) (FDA-approved drugs) were found to be effective against pneumonic plague. Furthermore, amoxapine (AXPN) is a potential drug that can protect against respiratory infections like Klebsiella pneumonia [44].

\section{Antidepressants against leishmaniasis}

A study of antileishmanial activity of imipramine has been conducted using isolated liver parts from leishmania infected animals to observe the status of granuloma formation in the liver of diseased and imipramine treated animals [45]. It was observed that Leishmania infected animals had less developed hepatic granuloma with fewer numbers of lymphocytes, while imipramine treated animal liver showed developed hepatic granuloma with more lymphocytes [46-49]. Treatment of animals with mirtazapine which is an atypical antidepressant activates macrophages in the liver. This activation increases the ability of these cells to kill bacteria and, at the same time, reduces the overall inflammation. This reprogramming of the liver results in a prominent immune response and subsequent elimination of pathogen, while limiting collateral damage mediated by hepatic inflammation [50].

Imipramine has also shown potential anti-leishmanial activity against $L$. donovani parasites sensitive and resistant towards antimonials at a significantly lower dose with a short duration of the treatment without any toxic side effects when encapsulated in squalene-phosphatidylcholine [51]. The antidepressant imipramine is an effective anti-leishmanial agent in the hamster model. Imipramine can change the PMF (proton motive force) so that the proton movement across the membrane of $L$. donovani is disturbed [52]. As an immune modulator, the drug increases TNF- $\alpha$, which has strong inhibitory properties against the causative parasite [53]. Desipramine, the metabolite of imipramine, has been shown to have antileishmanial property against $L$. donovani promastigotes $[47,54]$. Additionally, imipramine is effective against antimony-safe intracellular amastigotes without affecting the host cells [25]. A structural study reported imipramine analogues also have potential antileishmanial activity [55]. Tricyclic antidepressants have an affinity towards phospholipids, thus altering cellular protein and lipid levels of the parasite [47] (Fig 2 and Fig 3). Another intriguing element of imipramine is its effect on the enzyme methyltransferases which is responsible for the transfer of the methyl group. Imipramine can repress the catechol-0methyltransferase (COMT) action and affect the methylation of phospholipid in the lipid bilayer $[55,56]$ fig. 4 . The biosynthesis of sterol in the Leishmania parasite has the end goal that these parasites produce ergosterol subsidiaries rather than cholesterol
[57]. The C-24 methyltransferase is involved in the methylation for the last few steps during the biosynthesis of sterol in the Leishmania parasite. However, in mammalian cholesterol synthesis, these steps are not present [58]. Tricyclic antidepressants cause cellular damage or cell apoptosis of the Leishmania parasite by non-specific mechanisms like increasing permeability of the cell membrane, inhibiting the proline transport (fig. 2) and reducing $\Delta \mathrm{pH}$ and cellular ATP at relatively high concentrations [52]. Mianserin, an antidepressant shows anti-leishmanial activity mainly in the case of visceral leishmaniasis. The $50 \%$ inhibition of both the promastigote and amastigote forms of the parasite has been reported upon Mianserin treatment at the concentrations of $21 \mu \mathrm{M}$ and $46 \mu \mathrm{M}$, respectively. While it has also been reported that mianserin-treated promastigotes have a 2.5 -fold reduction in ergosterol as compared to the untreated control parasites [59]. Docking and ADME studies have also shown potential antileishmanial activity of various imipramine analogues [60].

The antidepressant sertraline (SSRI) alters the bioenergetic metabolism of the parasite (Leishmania infantum). This caused a notable variation in the stages of redox reaction in the thiol group and intracellular amino acids deficiency which are essential for the metabolic functions of Leishmania. Sertraline can kill Leishmania parasites in multiple ways that ultimately affect its vital metabolic steps. In the case of visceral leishmaniasis, sertraline is a very important drug [61]. Ketanserin, an antidepressant also has the same inhibitory action as mianserin with a similar mechanism of action against the promastigotes and amastigote forms of the parasite [62].

Quinolizidine-Derived lucanthone and amitriptyline analogues are also found to be active against each species of flagellated protozoa $L$. tropical and L. infantum promastigotes with IC50 values within the low micromolar range, higher efficiency than miltefosine, with considerably lower toxicity in Vero-76 cells. Recent studies have recommended that the inhibition of trypanothione reductase enzyme (TryR) may also lead to anti-leishmanial activity [63]. Trypanothione reductase (TryR) plays a very important role in redox reaction which converts trypanothione disulphide to its reduced state $\left(\mathrm{T}[\mathrm{SH}]_{2}\right)$. This thiol, trypanothione $\left(\mathrm{T}[\mathrm{SH}]_{2}\right)$, gives Leishmania parasites a unique oxidative defence mechanism that helps their survival within the host macrophage [64]. Both lucanthone and amitriptyline analogues are believed to inhibit the trypanothione reductase enzyme [62].

\section{Antidepressant and leishmaniasis: experimental evidence}

Sodium stibogluconate sensitive and resistant strains were treated with tricyclic antidepressants. IC50 and EC50 of imipramine were found to be similar in both strains irrespective of Sodium stibogluconate sensitivity $[47,65]$.

Reductions of mitochondrial transmembrane potential by imipramine lead to the death of Leishmania parasites [66]. A combination of imipramine [67] and miltefosine were utilized for this purpose [68]. After 7-8 h of treatment with imipramine, it was observed that the mitochondrial transmembrane potential significantly reduced, in case of both the sodium stibogluconate resistant and sodium stibogluconate sensitive strains. Miltefosine alone was unable to alter mitochondrial transmembrane potential after 7-8 $\mathrm{h}$ of treatment. After the 7-8 $\mathrm{h}$ of imipramine exposure to the resistant strain, BHU 575, more than $50 \%$ parasitic cells were dead, while miltefosine alone prompted less than $6 \%$ parasitic cell death [69]. Thus, tricyclic antidepressant, imipramine was found to be more potent and efficacious than miltefosine. Imipramine was also found to be non-toxic to macrophages [47, 70].

The replication rate of Leishmania donovani within macrophage in the presence of tricyclic antidepressants have been carried out to determine the effects of the studied drugs against the Leishmania parasite. The antidepressants suppressed parasitic replication even in the absence of sodium stibogluconate $[47,71]$.

NO (Nitric oxide) and Reactive Oxygen Species (ROS) are two significant leishmanicidal agents. Seven to eight hours after the treatment of infected macrophages with a tricyclic antidepressant, 
ROS levels were reported to increase, while maximum NO generation was observed after 20 h of exposure with the compound $[47,72]$.

\section{Leishmanicidal action of sertraline}

The promastigotes of Leishmania infantum has also been found to be affected by the antidepressant sertraline. The IC50 and IC90 values of sertraline for promastigotes of Leishmania infantum are reported to be in the range of $1.3-2.7 \mu \mathrm{M}$ and 6.6$10.2 \mu \mathrm{M}$, respectively. However, in the case of the amastigotes the IC50 and the IC 90 values were within the range of $3.6 \mu \mathrm{M}-4.2$ $\mu \mathrm{M}$ and $7.8 \mu \mathrm{M}-8 \mu \mathrm{M}$, respectively. Sertraline was also nontoxic toward experimental murine macrophages upto $80 \mu \mathrm{M}$ concentration [61].

Sertraline prompted the destruction of the plasma membrane of promastigotes of Leishmania infantum: It interrupted the bioenergetics of Leishmania species by altering the permeability of the plasma membrane of the parasite while also blocking the cell cycle and intracellular ATP levels of Leishmania [61, 73]. Sertraline altered the mitochondrial functions of promastigotes of Leishmania infantum. The reduced ATP level by sertraline reduced the cell membrane permeability and mitochondrial oxidative phosphorylation of the parasite. Flow cytometric analysis showed that sertraline reduced mitochondrial electrochemical potential to reduce ATP level and inhibited the build-up of rhodamine-123 in Leishmania infantum promastigotes. Sertraline not only altered the functions of the promastigotes but also changed their mitochondrion morphology. Similar results were also observed for the amastigote stage of the parasite $[61,74]$. Sertraline also interrupted the metabolism of the parasitic promastigotes by altering the lipid bilayer $[61,75]$.
To study the role of anti-depressants on leishmania mediated altered immunity, rodents were infected with wild-type and resistant $L$. donovani parasites and their immune status were determined. For this experiment splenic tissue consisting of $\mathrm{B}$ and $\mathrm{T}$ lymphocytes were isolated from the experimental animals. After isolation, the splenic tissue was treated with soluble Leishmanial antigen which was prepared from the L. donovani promastigotes or by Con A (nonspecific mitogen) [76]. Immune reactions were not observed for diseased animals with and without imipramine treatment $[47,76]$. Diseased and antidepressant drug (imipramine) treated rodent animals were used to measure inducible nitric oxide synthase and cytokine gene expression. The study showed that antidepressants (imipramine) increased interferon- $\gamma$, tissue necrosis factor- $\alpha$ and inducible nitric oxide synthase while decreasing interleukin-10 and tissue growth factor- $\beta$ levels suggesting its immunomodulatory actions [47]. Diseased and drug (imipramine) treated animals were also tested for granuloma formation. Leishmania donovani infected rodents were found to have less developed immune cells or granuloma and fewer T and B lymphocytes, whereas the drugtreated rodent animals showed enough developed immune cells or granulomas and lymphocytes [45-49].

\section{CONCLUSION}

The discussed literature on role of antidepressants on leishmaniasis shows some promising observations on how antidepressants like imipramine and sertraline may be effective against both wild-type and drug-resistant leishmanial parasites. However, the area warrants further research to clearly understand the mechanisms of action of the given drug in vivo and in the infected individuals.

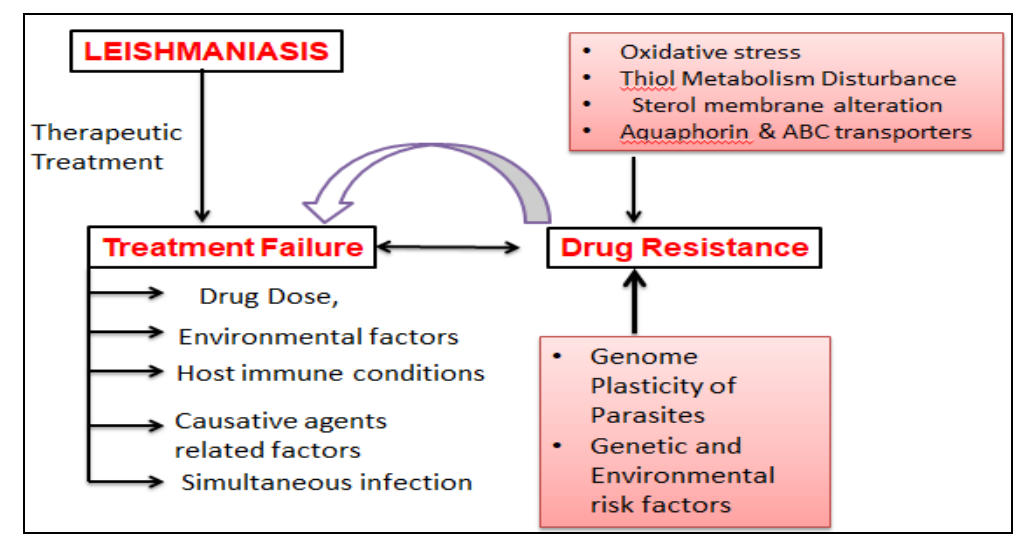

Fig. 1: Lists of factors that impact drug resistance and treatment failure [29]

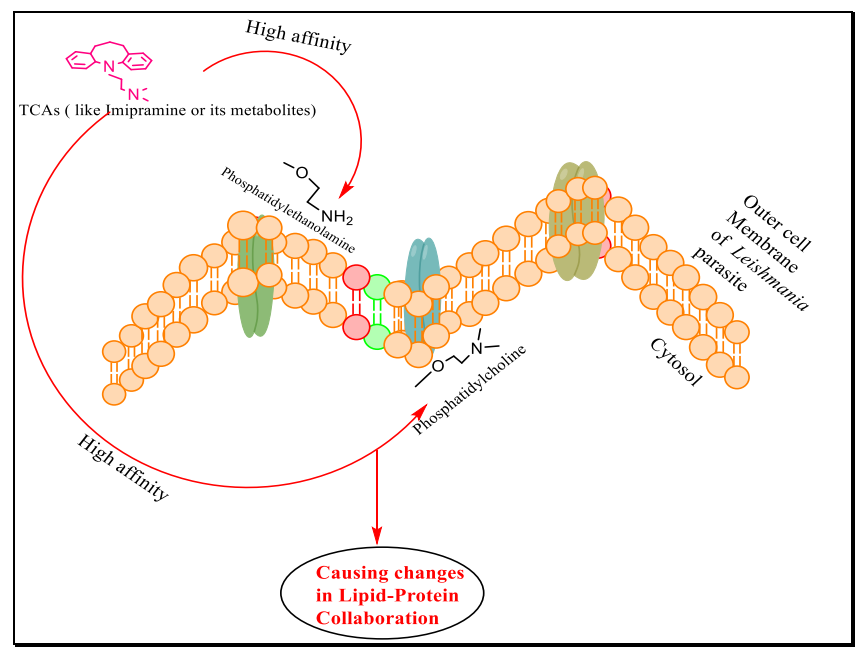

Fig. 2: Tricyclic antidepressants have a great proclivity for mainly two types of phospholipids, namely phosphatidylcholine and phosphatidylethanolamine in lipid layers of the Leishmania cell membrane, causing changes in the lipid-protein ratio, which leads to cell death due to less energy production by the parasitic cells to survive inside the host cell [47] 


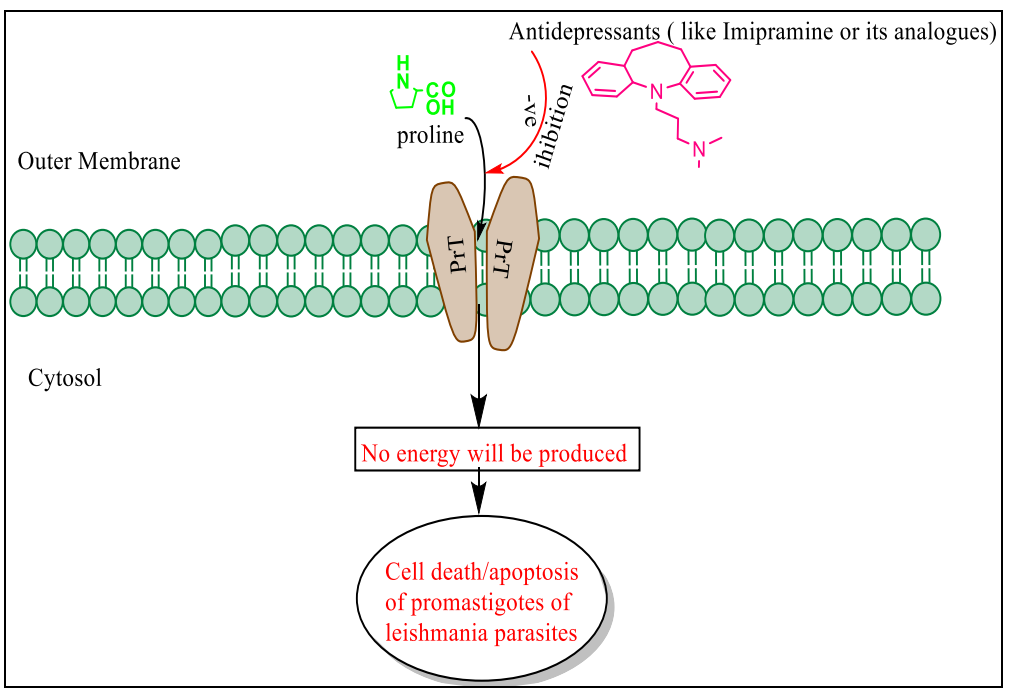

Fig. 3: Antidepressants like tricyclic antidepressants such as imipramine or its analogues inhibit the proline transport (PRT) into the cytosol of the Leishmania parasites so that less energy will be produced for survival of the promastigote form of the parasites [52]

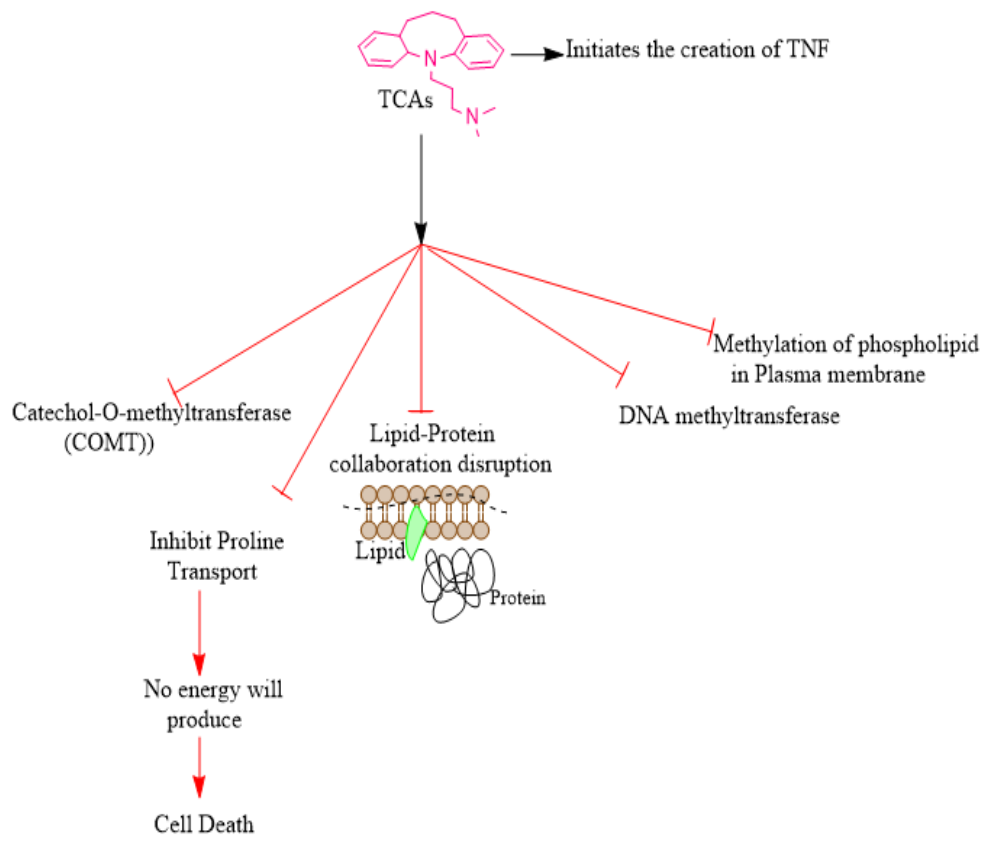

Fig. 4: Proposed mechanisms of action tricyclics against leishmaniasis

Tricyclic antidepressants (imipramine or its analogues) cause early apoptosis of Leishmania promastigotes and amastigotes. Imipramine or its derivatives inhibit the protein transport, ultimately leading to apoptosis [52]. They also cause lipid-protein disruption causing changes in the lipid-protein ratio, which leads to cell death due to less energy production by the parasitic cells to survive into the host cell [47]. These antidepressants also have an inhibitory action on parasitic DNA methyltransferase and catecholo-methyl transferase (COMT), causing altered parasitic cellular metabolism.

Table 1: Causative agents of leishmaniasis

\begin{tabular}{|c|c|c|}
\hline Species & Clinical diseases & Source \\
\hline Leishmania aethiopica & Localised cutaneous leishmaniasis, diffuse cutaneous leishmaniasis & {$[77,78]$} \\
\hline Leishmania amazonensis & Localised cutaneous leishmaniasis, diffuse cutaneous leishmaniasis, mucocutaneous leishmaniasis & {$[78,79]$} \\
\hline Leishmania donovani & Visceral leishmaniasis & {$[77,79]$} \\
\hline Leishmania infantum & Cutaneous leishmaniasis, visceral leishmaniasis & {$[77,78]$} \\
\hline Leishmania major & Cutaneous leishmaniasis & {$[77,79]$} \\
\hline Leishmania mexicana & Localised cutaneous leishmaniasis, diffuse cutaneous leishmaniasis & {$[78,79]$} \\
\hline Leishmania braziliensis & Localised cutaneous leishmaniasis, mucocutaneous leishmaniasis & {$[77,78]$} \\
\hline Leishmania lainsoni & Localised cutaneous leishmaniasis & {$[77,78]$} \\
\hline Leishmania shawi & Localised cutaneous leishmaniasis & {$[78,79]$} \\
\hline Leishmania martiniquensis & Visceral leishmaniasis, localised cutaneous leishmaniasis & {$[77,79]$} \\
\hline
\end{tabular}


Table 2: Classical antidepressants

\begin{tabular}{lll}
\hline Antidepressant class & Name of drugs \\
\hline Selective Serotonin Reuptake Inhibitors (SSRIs) & Setraline, Citalopram, Fluoxitine \\
Serotonin and Norepinephrine Reuptake Inhibitirs (SNRIs) & Duloxetine & Mirtazapine \\
Serotonin Receptor Antagonists & Imipramine, Trimipramine, Amitriptyline, Desipramine \\
Tricyclic Antidepressants (TCAs) & [18] \\
\hline
\end{tabular}

\section{ACKNOWLEDGEMENT}

We acknowledge Prof (Dr) Syamal Roy for his valuable inputs, which helped us improve the scientific quality of the manuscript. We also acknowledge NIPER-Kolkata for extending infrastructural support.

\section{FUNDING}

Nil

\section{AUTHORS CONTRIBUTIONS}

All the authors have contributed equally.

\section{CONFLICT OF INTERESTS}

Declared none

\section{REFERENCES}

1. Kumar GA, Karmakar J, Mandal C, Chattopadhyay A. Leishmania donovani internalizes into host cells via caveolin-mediated endocytosis. Sci Rep. 2019;9(1):12636. doi: 10.1038/s41598019-49007-1, PMID 31477757.

2. De Freitas EO, Leoratti FMdS, Freire-de-Lima CG, Morrot A, Feijo DF. The contribution of evasive immune mechanisms to parasite persistence in visceral leishmaniasis. Front Immunol. 2016;7:153. doi: 10.3389/fimmu.2016.00153, PMID 27148272.

3. Manhas R, Tandon S, Sen SS, Tiwari N, Munde M, Madhubala R. Leishmania donovani parasites are inhibited by the benzoxaborole AN2690 targeting leucyl-tRNA synthetase. Antimicrob Agents Chemother. 2018;62(9):e00079-18. doi: 10.1128/AAC.00079-18, PMID 29941647.

4. Kariyawasam KKGDUL, Selvapandiyan A, Siriwardana HVYD, Dube A, Karunanayake P, Senanayake SASC, Dey R, Gannavaram S, Nakhasi HL, Karunaweera ND. Dermotropic leishmania donovani in Sri Lanka: visceralizing potential in clinical and preclinical studies. Parasitology. 2018;145(4):44352. doi: 10.1017/S003118201700169X, PMID 29113609.

5. Savoia D. Recent updates and perspectives on leishmaniasis. J Infect Dev Ctries. 2015;9(6):588-96. doi: 10.3855/jidc.6833, PMID 26142667.

6. Morimoto A, Uchida K, Chambers JK, Sato K, Hong J, Sanjoba C, Matsumoto Y, Yamagishi J, Goto Y. Hemophagocytosis induced by Leishmania donovani infection is beneficial to parasite survival within macrophages. PLOS Negl Trop Dis. 2019;13(11):e0007816. doi: 10.1371/journal.pntd.0007816. PMID 31738750.

7. Garrido Jareno M, Sahuquillo Torralba A, Chouman Arcas R, Castro Hernandez I, Molina Moreno JM, Llavador Ros M, Gomez Ruiz MD, Lopez Hontangas JL, Botella Estrada R, Salavert Lleti M, Peman Garcia J. Cutaneous and mucocutaneous leishmaniasis: experience of a mediterranean hospital. Parasit Vectors. 2020;13(1):24. doi: 10.1186/s13071-020-3901-1, PMID 31931865.

8. Bouazizi Ben Messaoud HB-B, Guichard M, Lawton P, Delton I, Azzouz Maache S. Changes in lipid and fatty acid composition during intramacrophagic transformation of Leishmania donovani complex promastigotes into amastigotes. Lipids. 2017;52(5):433-41. doi: 10.1007/s11745-017-4233-6, PMID 28161835.

9. Lockard RD, Wilson ME, Rodriguez NE. Sex-related differences in immune response and symptomatic manifestations to infection with leishmania species. J Immunol Res. 2019;2019:4103819. doi: 10.1155/2019/4103819, PMID 30756088.

10. Rodrigues V, Cordeiro-da-Silva A, Laforge M, Silvestre R, Estaquier J. Regulation of immunity during visceral leishmania infection. Parasit Vectors. 2016;9(1):118.

doi: 10.1186/s13071-016-1412-x, PMID 26932389.

11. Van Griensven J, Diro E. Visceral leishmaniasis: recent advances in diagnostics and treatment regimens. Infect Dis Clin North Am. 2019;33(1):79-99. doi: 10.1016/j.idc.2018.10.005, PMID 30712769.

12. Peters NC, Egen JG, Secundino N, Debrabant A, Kimblin N, Kamhawi S, Lawyer P, Fay MP, Germain RN, Sacks D. In vivo imaging reveals an essential role for neutrophils in leishmaniasis transmitted by sand flies. Science. 2008;321(5891):970-4. doi: 10.1126/science.1159194, PMID 18703742 .

13. Ribeiro-de-Jesus A, Almeida RPd, Lessa H, Bacellar O, Carvalho EM. Cytokine profile and pathology in human leishmaniasis. Braz J Med Biol Res. 1998;31(1):143-8. doi: 10.1590/s0100879x1998000100020, PMID 9686192.

14. Ohjijcpr EG. An overview of the azoles of interest. Int J Curr Pharm Res. 2015;7(1):1-6.

15. Hendrickx S, Guerin PJ, Caljon G, Croft SL, Maes L. Evaluating drug resistance in visceral leishmaniasis: the challenges. Parasitology. 2018;145(4):453-63. doi: 10.1017/ S0031182016002031, PMID 27866478.

16. Regli IB, Fernandez OL, Martinez Salazar B, Gomez MA, Saravia NG, Tacchini Cottier F. Resistance of leishmania (Viannia) panamensis to meglumine antimoniate or miltefosine modulates neutrophil effector functions. Front Immunol. 2018;9:3040. doi: 10.3389/fimmu.2018.03040, PMID 30622537.

17. Ghorbani M, Farhoudi R. Leishmaniasis in humans: drug or vaccine therapy? Drug Des Dev Ther. 2018;12:25-40. doi: 10.2147/DDDT.S146521. PMID 29317800.

18. Bérard A, Zhao JP, Sheehy O. Antidepressant use during pregnancy and the risk of major congenital malformations in a cohort of depressed pregnant women: an updated analysis of the quebec pregnancy cohort. BMJ Open. 2017;7(1):e013372. doi: 10.1136/bmjopen-2016-013372, PMID 28082367.

19. Chakravarty J, Sundar S. Drug resistance in leishmaniasis. J Glob Infect Dis. 2010;2(2):167-76. doi: 10.4103/0974-777X.62887, PMID 20606973.

20. Sundar S, Singh A, Rai M, Prajapati VK, Singh AK, Ostyn B, Boelaert M, Dujardin JC, Chakravarty J. Efficacy of miltefosine in the treatment of visceral leishmaniasis in India after a decade of use. Clin Infect Dis. 2012;55(4):543-50. doi: 10.1093/cid/cis474, PMID 22573856.

21. Dorlo TP, Balasegaram M, Beijnen JH, de Vries PJ. Miltefosine: a review of its pharmacology and therapeutic efficacy in the treatment of leishmaniasis. J Antimicrob Chemother. 2012;67(11):2576-97. doi: 10.1093/jac/dks275, PMID 22833634.

22. Sundar S, Thakur BB, Tandon AK, Agrawal NR, Mishra CP, Mahapatra TM, Singh VP. Clinicoepidemiological study of drug resistance in Indian kala-azar. BMJ. 1994;308(6924):307. doi: 10.1136/bmj.308.6924.307, PMID 8124119.

23. Sundar S, Murray HW. Availability of miltefosine for the treatment of kala-azar in India. Bull World Health Organ. 2005;83(5):394-5. doi: /S0042-96862005000500018, PMID 15976883.

24. Sundar S, Sinha PR, Agrawal NK, Srivastava R, Rainey PM, Berman JD, Murray HW, Singh VP. A cluster of cases of severe cardiotoxicity among kala-azar patients treated with a highosmolarity lot of sodium antimony gluconate. Am J Trop Med Hyg. 1998;59(1):139-43. doi: 10.4269/ajtmh.1998.59.139, PMID 9684642.

25. Andrade Neto VV, Pereira TM, do Canto Cavalheiro Md, Torres Santos EC. Imipramine alters the sterol profile in leishmania 
amazonensis and increases its sensitivity to miconazole. Parasit Vectors. 2016;9(1):183. doi: 10.1186/s13071-016-1467-8, PMID 27036654.

26. Marquis N, Gourbal B, Rosen BP, Mukhopadhyay R, Ouellette M. Modulation in aquaglyceroporin AQP1 gene transcript levels in drug-resistant Leishmania. Mol Microbiol. 2005;57(6):1690-9. doi: 10.1111/j.1365-2958.2005.04782.x. PMID 16135234.

27. Légaré D, Richard D, Mukhopadhyay R, Stierhof YD, Rosen BP, Haimeur A, Papadopoulou B, Ouellette M. The leishmania ATPbinding cassette protein PGPA is an intracellular metal-thiol transporter ATPase. J Biol Chem. 2001;276(28):26301-7. doi: 10.1074/jbc.M102351200. PMID 11306588.

28. Ashutosh, Sundar S, Goyal N. Molecular mechanisms of antimony resistance in Leishmania. J Med Microbiol. 2007;56(2):143-53. doi: 10.1099/jmm.0.46841-0. PMID 17244793.

29. Ponte Sucre A, Gamarro F, Dujardin JC, Barrett MP, Lopez Velez R, Garcia Hernandez R, Pountain AW, Mwenechanya R, Papadopoulou B. Drug resistance and treatment failure in leishmaniasis: A 21st century challenge. PLOS Negl Trop Dis. 2017;11(12):e0006052. doi: 10.1371/journal.pntd.0006052. PMID 29240765.

30. Meleppurakkal S, KS, DJ. Effect of selected yoga techniques along with ashwagandha and vacha in depression in the age group 65-75 YEARS. Asian J Pharm Clin Res 2021;14:65-8. doi: 10.22159/ajpcr.2021.v14i11.42259.

31. Alvano SA, Zieher LM. An updated classification of antidepressants: A proposal to simplify treatment. Personalized Medicine in Psychiatry. 2020;19-20. doi: 10.1016/j.pmip.2019.04.002.

32. Rani S, Sindhu N, Saini R, Pandey AK, Narwat A, Garg S. Comparison of the effects of antidepressants on cognition functions in patients of major depressive disorders in tertiary care hospital in haryana. Asian J Pharm Clin Res 2021;14:13440. doi: 10.22159/ajpcr.2021.v14i3.40467.

33. Obonaga R, Fernandez OL, Valderrama L, Rubiano LC, Castro Mdel M, Barrera MC, Gomez MA, Gore Saravia N. Treatment failure and miltefosine susceptibility in dermal leishmaniasis caused by Leishmania subgenus Viannia species. Antimicrob Agents Chemother. 2014;58(1):144-52. doi: 10.1128/AAC.01023-13, PMID 24145529.

34. Chen JY, Ren Y, Yan P, Belina ME, Chung RT, Butt AA. Tricyclic antidepressant use and the risk of fibrosis progression in hepatitis C-infected persons: results from erchives. J Viral Hepat. 2018;25(7):825-33. doi: 10.1111/jvh.12884, PMID 29478294.

35. Quillin III RC, Wilson GC, Nojima H, Freeman CM, Wang J, Schuster RM, Blanchard JA, Edwards MJ, Gandhi CR, Gulbins E, Lentsch $\mathrm{AB}$. Inhibition of acidic sphingomyelinase reduces established hepatic fibrosis in mice. Hepatol Res. 2015;45(3):305-14. doi: 10.1111/hepr.12352, PMID 24796378.

36. Fucho R, Martinez L, Baulies A, Torres S, Tarrats N, Fernandez A, Ribas V, Astudillo AM, Balsinde J, Garcia Roves P, Elena M, Bergheim I, Lotersztajn S, Trautwein C, Appelqvist H, Paton AW, Paton JC, Czaja MJ, Kaplowitz N, Fernandez Checa JC, Garcia Ruiz C. ASMase regulates autophagy and lysosomal membrane permeabilization and its inhibition prevents early stage nonalcoholic steatohepatitis. J Hepatol. 2014;61(5):1126-34. doi: 10.1016/j.jhep.2014.06.009. PMID 24946279.

37. Singh SP, Singh V, Kar N, Chan K. Efficacy of antidepressants in treating the negative symptoms of chronic schizophrenia: a meta-analysis. Br J Psychiatry. 2010;197(3):174-9. doi: 10.1192/bjp.bp.109.067710, PMID 20807960.

38. Kenis G, Maes M. Effects of antidepressants on the production of cytokines. Int J Neuropsychopharmacol. 2002;5(4):401-12. doi: 10.1017/S1461145702003164, PMID 12466038.

39. Arteaga Henriquez G, Simon MS, Burger B, Weidinger E, Wijkhuijs A, Arolt V, Birkenhager TK, Musil R, Muller N, Drexhage HA. Low-grade inflammation as a predictor of antidepressant and anti-inflammatory therapy response in MDD patients: a systematic review of the literature in combination with an analysis of experimental data collected in the EU-moodinflame consortium. Front Psychiatry. 2019;10:458. doi: 10.3389/fpsyt.2019.00458, PMID 31354538.
40. Zhang J, Yue Y, Thapa A, Fang J, Zhao S, Shi W, Yang Z, Li Y, Yuan Y. Baseline serum C-reactive protein levels may predict antidepressant treatment responses in patients with major depressive disorder. J Affect Disord. 2019;250:432-8. doi: 10.1016/j.jad.2019.03.001. PMID 30878656.

41. Wiedłocha M, Marcinowicz P, Krupa R, Janoska Jazdzik M, Janus M, Dębowska W. Effect of antidepressant treatment on peripheral inflammation markers- A meta-analysis. Prog Neuropsychopharmacol Biol Psychiatry. 2018;80(C):217-26. doi: $\quad 10.1016 /$ j.pnpbp.2017.04.026, PMID 28445690. pnpbp.2017.04.026.

42. Maes M. The immunoregulatory effects of antidepressants. Hum Psychopharmacol. 2001;16(1):95-103. doi: 10.1002/hup.191, PMID 12404604.

43. Wichit S, Hamel R, Bernard E, Talignani L, Diop F, Ferraris P. Imipramine inhibits Chikungunya virus replication in human skin fibroblasts through interference with intracellular cholesterol trafficking. Sci Rep. 2017;7(1):3145. doi: 10.1038/s41598-017-03316-5, PMID 28600536.

44. Andersson JA, Sha J, Kirtley ML, Reyes E, Fitts EC, Dann SM, Chopra AK. Combating multidrug-resistant pathogens with host-directed nonantibiotic therapeutics. Antimicrob Agents Chemother. 2018;62(1):e01943-17. doi: 10.1128/AAC.0194317, PMID 29109161.

45. Murray HW. Tissue granuloma structure-function in experimental visceral leishmaniasis. Int J Exp Pathol. 2001;82(5):249-67. doi: 10.1046/j.1365-2613.2001.00199.x. PMID 11703536.

46. Kaye PM, Svensson M, Ato M, Maroof A, Polley R, Stager S, Zubairi S, Engwerda CR. The immunopathology of experimental visceral leishmaniasis. Immunol Rev. 2004;201(1):239-53. doi: 10.1111/j.0105-2896.2004.00188.x. PMID 15361245.

47. Mukherjee S, Mukherjee B, Mukhopadhyay R, Naskar K, Sundar S, Dujardin JC, Das AK, Roy S. Imipramine is an orally active drug against both antimony sensitive and resistant Leishmania donovani clinical isolates in experimental infection. PLOS Negl Trop Dis. 2012;6(12):e1987. doi: 10.1371/journal.pntd.0001987. PMID 23301108.

48. Stager S, Alexander J, Carter KC, Brombacher F, Kaye PM. Both interleukin-4 (IL-4) and IL-4 receptor $\alpha$ signaling contribute to the development of hepatic granulomas with optimal antileishmanial activity. Infect Immun. 2003;71(8):4804-7. doi: 10.1128/IAI.71.8.4804-4807.2003, PMID 12874364.

49. Stanley AC, Engwerda CR. Balancing immunity and pathology in visceral leishmaniasis. Immunol Cell Biol. 2007;85(2):138-47. doi: 10.1038/sj.icb7100011. PMID 17146466.

50. Davis RP, Almishri W, Jenne CN, Swain MG. The antidepressant mirtazapine activates hepatic macrophages, facilitating pathogen clearance while limiting tissue damage in mice. Front Immunol. 2020;11:578654. doi: 10.3389/fimmu.2020.578654, PMID 33250892.

51. Mukherjee S, Pradhan S, Ghosh S, Sundar S, Das S, Mukherjee B, Roy S. Short-course treatment with imipramine entrapped in squalene liposomes results in sterile cure of experimental visceral leishmaniasis induced by antimony resistant Leishmania donovani with increased efficacy. Front Cell Infect Microbiol. 2020;10:595415. doi: 10.3389/fcimb.2020.595415, PMID 33240825.

52. Zilberstein D, Liveanu V, Gepstein A. Tricyclic drugs reduce proton motive force in Leishmania donovani promastigotes. Biochem Pharmacol. 1990;39(5):935-40. doi: 10.1016/00062952(90)90210-c, PMID 1968745.

53. Kubera M, Kenis G, Bosmans E, Kajta M, Basta Kaim A, Scharpe S, Budziszewska B, Maes M. Stimulatory effect of antidepressants on the production of IL-6. Int Immunopharmacol. 2004;4(2):185-92. doi: 10.1016/j.intimp.2003.11.006. PMID 14996410.

54. Evans AT, Croft SL. Antileishmanial actions of tricyclic neuroleptics appear to lack structural specificity. Biochem Pharmacol. 1994;48(3):613-6. doi: 10.1016/00062952(94)90293-3, PMID 7915114.

55. Fisar Z. Interactions between tricyclic antidepressants and phospholipid bilayer membranes. Gen Physiol Biophys. 2005;24(2):161-80. PMID 16118470. 
56. Zimmermann N, Zschocke J, Perisic T, Yu S, Holsboer F, Rein T. Antidepressants inhibit DNA methyltransferase 1 through reducing G9a levels. Biochem J. 2012;448(1):93-102. doi: 10.1042/BJ20120674, PMID 22880885.

57. Ahyayauch $\mathrm{H}$, Bennouna $\mathrm{M}$. Interaction of chlorpromazine and imipramine with model membranes. Therapie. 1999;54(5):585-8. PMID 10667094.

58. Lorente SO, Rodrigues JC, Jimenez Jimenez C, Joyce Menekse M, Rodrigues C, Croft SL, Yardley V, de Luca Fradley K, Ruiz Perez LM, Urbina J, de Souza W, Gonzalez Pacanowska D, Gilbert IH. Novel azasterols as potential agents for the treatment of leishmaniasis and trypanosomiasis. Antimicrob Agents Chemother. 2004;48(8):2937-50. doi: 10.1128/AAC.48.8.29372950.2004. PMID 15273104.

59. Dinesh N, Kaur PK, Swamy KK, Singh S. Mianserin, an antidepressant kills leishmania donovani by depleting ergosterol levels. Exp Parasitol. 2014;144:84-90. doi: 10.1016/j.exppara.2014.06.004.exppara.2014.06.004. PMID 24950381.

60. Pandey RK, Verma P, Sharma D, Bhatt TK, Sundar S, Prajapati VKJB. High-throughput virtual screening and quantum mechanics approach to develop imipramine analogues as leads against trypanothione reductase of leishmania. Biomed Pharmacother. 2016;83:141-52. doi: 10.1016/j.biopha.2016.06.010, PMID 27470561. biopha.2016.06.010.

61. Lima ML, Abengozar MA, Nacher-Vazquez M, Martinez-Alcazar MP, Barbas C, Tempone AG, Lopez-Gonzalvez A, Rivas L. Molecular basis of the leishmanicidal activity of the antidepressant sertraline as a drug repurposing candidate. Antimicrob Agents Chemother. 2018;62(12):e01928-18. doi: 10.1128/AAC.01928-18, PMID 30297370.

62. Singh S, Dinesh N, Kaur PK, Shamiulla B. Ketanserin, an antidepressant, exerts its antileishmanial action via inhibition of 3-hydroxy-3-methylglutaryl coenzyme a reductase (HMGR) enzyme of Leishmania donovani. J Parasitol Res. 2014;113(6):2161-8. doi: 10.1007/s00436-014-3868-y, PMID 24728519.

63. Alpizar Sosa EA. Polyomic characterization of polyene drug resistance in Leishmania spp. University of Glasgow; 2020.

64. Kumar A, Chauhan N, Singh S. Understanding the cross-talk of redox metabolism and fe-s cluster biogenesis in leishmania through systems biology approach. Front Cell Infect Microbiol. 2019;9:15. doi: 10.3389/fcimb.2019.00015, PMID 30778378.

65. Mukhopadhyay R, Mukherjee S, Mukherjee B, Naskar K, Mondal D, Decuypere S. Characterisation of antimony-resistant leishmania donovani isolates: biochemical and biophysical studies and interaction with host cells. Int J Parasitol. 2011;41(13-14):1311-21. doi: 10.1016/j.ijpara.2011.07.013, PMID 21920365. ijpara.2011.07.013.

66. Reers M, Smith TW, Chen LB. J-aggregate formation of a carbocyanine as a quantitative fluorescent indicator of membrane potential. Biochemistry. 1991;30(18):4480-6. doi: 10.1021/bi00232a015, PMID 2021638.

67. Zilberstein D, Dwyer DM. Antidepressants cause lethal disruption of membrane function in the human protozoan parasite leishmania. Science. 1984;226(4677):977-9. doi: 10.1126/science.6505677, PMID 6505677.

68. Paris C, Loiseau PM, Bories C, Breard J. Miltefosine induces apoptosis-like death in Leishmania donovani promastigotes. Antimicrob Agents Chemother. 2004;48(3):852-9. doi: 10.1128/aacAAC.48.3.852-859.2004, PMID 14982775.
69. Bezabeh MF, Werbovetz KA, Murthy Krjijo AP, Murthy KVR. Formulation and evaluation of amphotericin $b$ and miltefosine combination nanovesicles. Int J App Pharm. 2021:74-8. doi: 10.22159/ijap.2021v13i3.40605.

70. Verma NK, Dey CS. Possible mechanism of miltefosinemediated death of Leishmania donovani. Antimicrob Agents Chemother. 2004;48(8):3010-5. doi: 10.1128/AAC.48.8.30103015.2004, PMID 15273114

71. Sen S, Roy K, Mukherjee S, Mukhopadhyay R, Roy S. Restoration of IFN $\gamma \mathrm{R}$ subunit assembly, IFN $\gamma$ signaling and parasite clearance in Leishmania donovani infected macrophages: role of membrane cholesterol. PLoOS Pathog. 2011;7(9):e1002229. doi: 10.1371/journal.ppat.1002229.ppat.1002229. PMID 21931549.

72. Mookerjee Basu J, Mookerjee A, Sen P, Bhaumik S, Sen P, Banerjee S, Naskar K, Choudhuri SK, Saha B, Raha S, Roy S. Sodium antimony gluconate induces generation of reactive oxygen species and nitric oxide via phosphoinositide 3-kinase and mitogen-activated protein kinase activation in Leishmania donovani-infected macrophages. Antimicrob Agents Chemother. 2006;50(5):1788-97. doi: 10.1128/AAC.50.5.17881797.2006, PMID 16641451.

73. Luque Ortega JR, Rivas L. Characterization of the leishmanicidal activity of antimicrobial peptides. Antimicrob Peptid Methods Mol Biol Springer. 2010;618:393-420. doi: 10.1007/978-160761-594-1_25, PMID 20094878.

74. Pan AA, Duboise SM, Eperon S, Rivas L, Hodgkinson V, Traub-Cseko Y. Developmental life cycle of leishmaniacultivation and characterization of cultured extracellular amastigotes 1. J Eukaryot Microbiol. 1993;40(2):213-23. doi: 10.1111/j.1550-7408.1993.tb04906.x.

75. Saunders EC, Ng WW, Kloehn J, Chambers JM, Ng M, McConville MJ. Induction of stringent metabolic response in intracellular stages of Leishmania mexicana leads to increased dependence on mitochondrial metabolism. PLoOS Pathog. 2014;10(1):e1003888. doi: 10.1371/journal.ppat.1003888.ppat.1003888. PMID 24465208.

76. Basu R, Bhaumik S, Basu JM, Naskar K, De T, Roy S. Kinetoplastid membrane protein-11 DNA vaccination induces complete protection against both pentavalent antimonialsensitive and-resistant strains of Leishmania donovani that correlates with inducible nitric oxide synthase activity and IL-4 generation: evidence for mixed Th1- and Th2-like responses in visceral leishmaniasis. J Immunol. 2005;174(11):7160-71. doi: 10.4049/jimmunol.174.11.7160, PMID 15905560.

77. Akhoundi M, Kuhls K, Cannet A, Votypka J, Marty P, Delaunay P, Sereno D. A historical overview of the classification, evolution, and dispersion of Leishmania parasites and sandflies. PLoOS Negl Trop Dis. 2016;10(3):e0004349. doi: 10.1371/journal.pntd.0004349.pntd.0004349. PMID 26937644.

78. Shaw J, Pratlong F, Floeter Winter L, Ishikawa E, El Baidouri F, Ravel C, Dedet JP. Characterization of leishmania (Leishmania) waltoni n. sp. (Kkinetoplastida: Trypanosomatidae), the parasite responsible for diffuse cutaneous leishmaniasis in the dominican republic. Am J Trop Med Hyg. 2015;93(3):552-8. doi: 10.4269/ajtmh.14-0774, PMID 26149864.

79. Espinosa OA, Serrano MG, Camargo EP, Teixeira MMG, Shaw JJ. An appraisal of the taxonomy and nomenclature of trypanosomatids presently classified as Leishmania and Endotrypanum. Parasitology. 2018;145(4):430-42. doi: 10.1017/S0031182016002092, PMID 27976601. 